\section{PHRENOLOGY APPLICABLE TO JURISPRUDENCE.}

\section{To the Editor of THE LANCET.}

Sir,-The last number of THE $\mathrm{L}_{\text {A NCET }}$ contains a letter from Dr. Dick, in reply to mine of the 8th ult. As this communication throws no light upon the matter in question, but leaves it precisely as it stood when I last addressed you, my only reason for noticing it arises from the circumstance that it contains a great number of misrepresentations, which cannot properly be suffered to pass without correction.

After some vague preliminary assertions, Dr. Dick proceeds to say,_- "Mr. Sampson resorts to that artifice in argument of seeking to make me appear responsible for extravagancies into which he is pleased to push my principles. He assumes, for example, because expressing myself in a general manner, I asserted that all men possess an undoubted perception of, and power of distinguishing between right and wrong, and an intuitive persuasion of being endowed with perfect volition in regard to their actions; and that, therefore, they must be presumed to possess such volition, and consequently to be responsible, that I must comprehend lunatics and idiots in the foregoing definition; and he takes leave to infer, that because it would be absurd to regard the latter as responsible agents, it must of necessity be equally so to view the former as such. Reasoning disingenuous like this neither merits nor requires reply."

Now, by those who are disposed to take a review of all that has passed upon the subject, it will be seen that the point at issue is simply this: Dr. Dick, in his first letter, denounced my views of criminal treatment, because they involve the proposition that the manifestation of the moral sentiments depends in this life upon material organs ; and he asserted in opposition to them, that man is endowed with a moral sense, which in its manifestation is entirely independent of physical conformation, and that the possession of this moral sense is a "measure" of his responsibility to punishment. To this $I$ replied, that if such be the case the furious lunatic and the mischievous idiot must be held as equally responsible to punishment with all other offenders, because insanity and idiotcy merely result from disorder or congenital defect of lrain, circumstances of which, according to Dr. Dick, the moral sense (the possession of which, be it remembered, is the "measure" of responsibility,) is entirely independent. At this point the argument still stands. Dr. Dick must either give up his proposition, that the manifestation of the moral sense is totally uninfluenced by the condition of the brain, or he must be prepared to maintain that the circumstance of the existence of disease or defect of brain should have no influence upon our estimate of the degree in which a human being is responsible to punishment.

Dr. Dick, therefore, makes a culpably careless assertion when he says that I " assume" that he comprehends lunatics and idiots annongst those who are responsible to the severities of the law. I do not assume anything of the sort, but draw it as a strictly logical inference from his own statements. The carelessness of his remark, also, that $\mathbf{I}$ " take leave to infer that because it would be absurd to regard lunatics as responsible agents, it must of necessity be equally so to view all other men as such," seems to me also open to censure, seeing that in my letter I do not take leave (however I might be warranted or otherwise in doing so) to make any inference of the kind.

Until Dr. Dick has taken his choice as to which horn of the dilemma in which he has placed himself he would prefer to fix upon, it is needless for me to pursue the subject further. I observe, that in explanation of his original statements he says, "What $I$ assert is, that so long as the intellect is sufficiently sound for all the ordinary purposes of life, the moral sense is always simultaneously sound to such a degree as to render the man responsible." But I cannot allow him to complicate the argument in this way: he must either keep to his original proposition, or he must openly abandon it. If he persists that the moral sense is independent of the brain, and that the possession of this moral sense is to be the measure of respon. sibility to punishment, then do I maintain that it follows as a logical sequence that no circumstance arising from mere disorder of the brain (as the loss of intellect through insanity, or the deficiency of it through congenital defect, can have anything to do with our estimate of the responsibility to punishment which the possession of that moral sense conveys. By taking this ground, I show the "extravagance" to which Dr. Dick's argument inevitably leads, and the inutility of entering into any serious discussion to refute it. If, on the other hand, $\mathbf{D r}$. Dick confesses that the manifestations of the moral sense are in some way connected with the brain, his objection to my views falls to the ground, and he thus retires from the discussion.

Towards the conclusion of his letter $\mathbf{D r}$. Dick has the following paragraph :- 6 Mr. Sampson requests me to define the nature and extent of the moral sense, the variations to which it is subject, \&c.; and from the tenor of this part of his paper I am led to suspect, though unwillingly, that he is doubtful if man possesses such a sense, at least in such a degree of completeness and accuracy as to constitute responsibility." Now I submit that in an argument upon a scientific subject, the introduction of mere suspicions, especially when these suspicions 
are of a personal nature, and appear to be /ingenuous reasoning," coupled wilh the introduced only for the purpose of exciting holding of views which are " wild," prejudice, is totally unjustifiable. Whatever "visionary," "shocking," "ludicrous," and I have stated in my writings is open to Dr. "dreadful," unless these charges are ac. Dick's remark; and if any of these state- companied by something like an attempt at ments require explanation, I shall be very happy to afford it. In the present instance the remarks of your correspondent are the less excusable, because I have avowed my. self a phrenologist; and the views taken by the disciples of this science regarding the moral sentiments are matter of notoriety. As, however, Dr. Dick appears to be ignorant of what these views are, I take this opportunity, although I cannot flatter myself that it can be a matter of the slightest interest to the readers of ThE LANCET, to relieve his mind, by assuring him that the suspicion which he so "unwillingly" entertains is entirely without foundation.

I am anxious to intrude as little as possible upon your space, but the following remarks are imperatively called for. In his first letter Dr. Dick charged Mr. Combe with having fallen into a "laughably incorrect analogy," by supposing that certain motions which he had observed in the brain of a young girl at New York arose from " muscular action," or something analogous to it. I showed to Dr. Dick that Mr. Combe had expressed no supposition of the kind, and I referred to the page of the work on America, by which he would ascertain that he had fallen into error. Dr. Dick takes no notice of this exposure of his inaccuracy, but allndes once more to the case in question only for the sake of giving forth another misrepresentation. He now says that Mr. Combe obviously meant to prove that the movements of the brain which he observed were "owing to the mind acting on the brain divectly," independently of the heart and lungs. I deny it to be the case that Mr. Combe " obviously" meant to prove any such thing, and I request Dr. Dick to quote to me the words of that gentleman which would lead to any inference of the kind. Meanwhile I call upon him, as he valuess a reputation for candour, to acknowledge the error into which he was betrayed, when he stated that Mr. Combe fancied the movements of the brain in the above-mentioned case to proceed from "muscular" action.

In conclusion, I beg to remark, that so long as Dr. Dick's communications upon the subject of my views find place in THE LANCET, I shall feel bound, out of respect to its readers and editor, to correct any misrepresentations which these communications may contain ; but you must at the same time allow me to protest against what I conceive to be some objectionable characteristics of Dr. Dick's singularly emphatic style, and to express an idea that a scientific journal should not be made the medium of charges against any one of "artifice" and "disdemonstration. If Dr. Dick will point out any passage in which $I$ have misunderstood, and consequently misrepresented, his ideas, I shall hasten to make the requisite correction. My sincere desire has been to arrive at a clear understanding of his views. That this has been a task of some difficulty (either owing to slowness of apprehension on the one side, or to a confused mode of reasoning on the other,) I do not hesitate to confess. I am, Sir, your very faithful and obedient servant,

\section{Clapham New Park, Surrey, M. B. Sampson. April 11, 1842.}

\section{MR. SIMPSON'S KEPHALEPSALIS.}

\section{To the Editor of The Lancet.}

Sir,-Permit me, through the medium of your valuable Journal, to request your cor. respondent, Dr. Davis, to betake limself to the ware-rooms of those cutlers in London who are in possession of $\mathrm{Mr}$. Simpson's kephalepsalis, and impartially compare that instrument with those contrivances for which it is but natural Dr. D. should be an advo. cate; and thereafter communicate to you his unbiassed opinion of the respective merits of the kephalepsalis and the osteotomist.

It was not until after these contrivances had been carefully examined by many of my brethren here, that I veutured to communicate to the professional public a description of Mr. Simpson's highly useful invention, which is as superior to the osteotomist, not only in point of utility, but also in as far as regards the facility with which the object of the practitioner may be attained, as a very sharp instrument can be to a blunt one. I must do Dr. Davis the justice to suppose that he could not have seen the kephalepsalis before communicating the article in the last number of THE LANCET,

Wh. Campbell, M.D., Lecturer on Midwifery, \&c. Picardy-place, Edinburgh, April 12, 1842.

\section{NOTE FROM DR. COOKSON.}

\section{To the Editor of THE LANCET.}

Sir,-If Mr. Hill thought his letter of any importance, why did he not publish it him. self when he published Mr. 10. K.'s answer? The omission is his own, not mine.

Your reader's will at once perceive that Mr. Hill's letter which appears for the first time, and Mr. D. K.'s letter which appears 